\title{
Modeling and Optimization of the BSCF-Based Single-Chamber Solid Oxide Fuel Cell by Artificial Neural Network and Genetic Algorithm
}

\author{
Minh-Vien Le, ${ }^{1}$ Tuan-Anh Nguyen ${ }^{(D)},{ }^{1}$ and T.-Anh-Nga Nguyen $\mathbb{D}^{2}$ \\ ${ }^{1}$ Faculty of Chemical Engineering, Ho Chi Minh City University of Technology, VNU-HCM, 268 Ly Thuong Kiet, \\ Ho Chi Minh City, Vietnam \\ ${ }^{2}$ Faculty of Applied Sciences, Ton Duc Thang University, 19 Nguyen Huu Tho Str., Tan Phong Ward, District 7, \\ Ho Chi Minh City, Vietnam \\ Correspondence should be addressed to Tuan-Anh Nguyen; anh.nguyen@hcmut.edu.vn and \\ T.-Anh-Nga Nguyen; nguyenthianhnga@tdtu.edu.vn
}

Received 21 February 2019; Revised 2 May 2019; Accepted 21 May 2019; Published 20 June 2019

Guest Editor: Thanh-Dong Pham

Copyright (C) 2019 Minh-Vien Le et al. This is an open access article distributed under the Creative Commons Attribution License, which permits unrestricted use, distribution, and reproduction in any medium, provided the original work is properly cited.

Fuel cells could be a highly effective and eco-friendly technology to transform chemical energy stored in fuel to useful electricity and thus are presently appraised as a standout among the most encouraging advancements for future energy demand. Solid oxide fuel cells (SOFCs) have several advantages over other types of fuel cells, such as the flexibility of fuel used, high energy conversion, and relatively inexpensive catalysts due to high-temperature operation. The single chambers, wherein the anode and cathode are exposed to the same mixture of fuel, are promising for the portable power application due to the simplified, compact, sealing-free cell structure. The empirical regression models, such as artificial neural networks (ANNs), can be used as a black-box tool to simulate systems without solving the complicated physical equations merely by utilizing available experimental data. In this study, the performance of the newly proposed BSCF/GDC-based cathode SOFC was modeled using ANNs. The cell voltage was estimated with cathode preparation temperature, cell operating temperature, and cell current as input parameters by the one-layer feed-forward neural network. In order to acquire the appropriate model, several network structures were tested, and the network was trained by backpropagation algorithms. The data used during the training, validation, and test are the actual experimental results from our previous study. The optimum conditions to achieve maximum power of the cell were then determined by the genetic algorithm and the developed ANN.

\section{Introduction}

Fuel cells could be a highly effective and eco-friendly technology to transform chemical energy stored in fuel to useful electricity and thus are presently appraised as a standout among the most encouraging advancements for future energy demand [1]. Among different classes of fuel cells, the solid oxide fuel cell (SOFC) has displayed an extraordinary integration of benefits, including high energy efficiency, broad fuel versatility, significant contamination allowance, and low waste discharge $[2,3]$. Currently, yttriastabilized zirconia (YSZ), a zirconia-based electrolyte, is the most widely utilized electrolyte as it has sufficient oxide-ion conductivity and, furthermore, demonstrates suitable phase durability in both oxidizing and reducing environments [4]. However, in order to lessen the ohmic polarization loss, the zirconia-based electrolyte needs a very high operation temperature $\sim 1000^{\circ} \mathrm{C}$, which provides adequate oxygen conductivity. Therefore, high temperature places rigorous constraints on its accompanying materials. Reducing the operation temperature to $500-800^{\circ} \mathrm{C}$, classified as the intermediate temperature range, is supposed to elongate the lifespan of SOFC, minimize its degradation rate, and diversify the range of material selections [5]. 
On the contrary, reducing operation temperature requires a new pair of electrolyte-cathode, which is more ion conductive than the conventional pair of Y-stabilized $\mathrm{ZrO}_{2}$ and $\left(\mathrm{La}_{1-x} \mathrm{Sr}_{x}\right) \mathrm{MnO}_{3}$. Therefore, the nickel cermet has been the unanimous selection for the anode composition. LAMOX is an oxide conductor family based initially on the parent $\mathrm{La}_{2} \mathrm{Mo}_{2} \mathrm{O}_{9}$ crystal. The lanthanide-doped LAMOX has the fundamental characteristics of an electrolyte at intermediate temperatures such as high ion conductivity $[6,7]$ and good phase stability [8]. However, the LAMOX composition is only occasionally investigated as the SOFC electrolyte.

On the cathode side, $\mathrm{Ba}_{0.5} \mathrm{Sr}_{0.5} \mathrm{Co}_{1-x} \mathrm{Fe}_{x} \mathrm{O}_{3-\delta}$ (BSCF) is usually suggested as a candidate in the intermediate temperature range, in perspective of its exceptional catalytic activity toward oxygen reduction combined with high ion conductivity [9], low electrochemical surface-exchange resistance [10], and reasonable fabrication cost [10]. However, the perovskite of BSCF does have its own drawback. The composition has the phase instability problem, similar to many other perovskites with cobalt on the B site [11]. It should be noted that the cathodic loss contributes the significant part of SOFC's polarization loss. The large cathode polarization loss normally occurs from the fact that the mixed conductor of the cathode perovskite frequently shows the ionic conductivity significantly lower than its electronic conductivity $[12,13]$. Hence, a composite cathode of ionic conductor and mixed conductor is adopted to minimize the cathodic loss.

The BSCF, gadolinium-doped ceria (GDC), and $\mathrm{La}_{1.8} \mathrm{Dy}_{0.2} \mathrm{Mo}_{2} \mathrm{O}_{9}$ (LDM) powders, therefore, were synthesized and characterized for fuel cell evaluation. The effect of different preparation conditions on the fuel cell behavior was found in this study. On the contrary, modeling and simulation of SOFCs are useful approaches to investigate effects of various design parameters and operating conditions on SOFC performances and also to help in SOFC improvements. The obtained results can be used in optimization, control, improvement, and design of the fuel cell system [14-16]. Currently, there are plenty of models that have been published to contribute more knowledge of the fuel cell phenomena. The approaches for fuel cell modeling can be classified into two categories: theoretical and empirical $[15,17,18]$. In the theoretical mathematical approach, the spatial dimensions of the models vary from simplified zero $(0-D)[19,20]$ and one (1-D) $[18,21-23]$ to more complex two (2-D) [24-27] and three (3-D) [28-30], with different characteristics and targets to different research purposes. The mathematical models, which are generally founded based on momentum, mass, and energy conservation laws, necessitate the information about many parameters and properties of the fuel cell system, the complicated equations, and the time-consuming numerical techniques. Therefore, using theoretical models makes the problem too complicated and impractical for some engineering applications.

Another approach, namely, empirical or data-driven modeling, might be more practical for the fuel cell user from the viewpoint the SOFC behavior can be inferred without deeply understanding the internal components [15, 17].
The empirical approaches can be applied to simulate the object's behavior without an algorithmic solution, merely by utilizing available experimental data. These approaches include least-squares support vector machine (LS-SVM) [31] and the Hammerstein model $[32,33]$. Among them, artificial neural network (ANN) presents some advantages such as high nonlinearity, matches experimental data with a low degree of error, and does not require any specific analytical equations and system descriptions. ANN is a black-box model, whereas numerical models allow for the examination of parameter distributions inside the cell. Numerical models may also be more accurate than ANN models if, for example, the operating conditions change significantly during dynamic operation. However, utilization of ANNs for modeling SOFCs appears a very promising way due to its rapid computation. Genetic algorithms (GAs) are a class of metaheuristic searching optimization techniques inspired by the mechanics of natural evolution and genetics [34]. Compared to conventional optimization methods, GAs are remarkably simple, robust, and able to handle the nondifferentiable, discontinuous, or multimodal problems. GAs have been successfully applied in a wide range of applications in various engineering, manufacturing, and management areas [35].

In this study, the performance of the BSCF/GDC-based cathode SOFC was modeled using ANNs. The cell voltage was estimated with cathode preparation temperature, cell operating temperature, and cell current as input parameters by the one-layer feed-forward neural network. In order to acquire the appropriate model, several network structures were tested, and the network was trained by backpropagation algorithms. The data used during the training, validation, and test have been obtained from the actual experimental results from our previous study [36]. The optimum condition to achieve maximum power was then determined by genetic algorithms and the developed ANN.

\section{Experiments and Methodology}

2.1. Experiments. The description of experimental configuration could be found in our study [36, 37]. The brief explanation of the cell is summarized as follows. The porous structure of the anode-supported cell was fabricated through the following steps. Commercial $\mathrm{NiO}(>99.5 \%), 1000^{\circ} \mathrm{C}$ calcined GDC, and $1000^{\circ} \mathrm{C}$ calcined LDM powders were mixed in a weight ratio of $4.8: 3.2: 0.8$. Then, the mixture was mixed with $15 \mathrm{wt} . \%$ of graphite flash, uniaxial pressed, and then sintered for $2 \mathrm{~h}$ at $1175^{\circ} \mathrm{C}$ to form an anode with a size of $\sim 0.4 \mathrm{~mm}$ in thickness and $\sim 13.2 \mathrm{~mm}$ in diameter.

$\mathrm{La}_{1.8} \mathrm{Dy}_{0.2} \mathrm{Mo}_{2} \mathrm{O}_{9}$ (LDM) electrolyte was applied to the polished porous anode pellet by the spin-coating method with a desired thickness of $\sim 60 \mu \mathrm{m}$. As mentioned above, BFSC cannot be applied directly onto LDM due to chemical reaction. Therefore, it needs an additional barrier layer to prevent undesirable reaction.

A barrier layer of 0.5 wt. $\% \mathrm{Fe}_{2} \mathrm{O}_{3}$-doped $\mathrm{Gd}_{0.1} \mathrm{Ce}_{0.9} \mathrm{O}_{1.95}$ (i-GDC) was applied on the LDM layer for one time to form $\mathrm{NiO}+\mathrm{GDC} / \mathrm{LDM} / \mathrm{i}-\mathrm{GDC}$ button. The button was then cosintered at $1225^{\circ} \mathrm{C}$ for 5 hours with a heating and cooling rate of $2^{\circ} \mathrm{C} \mathrm{min}^{-1}$. 
To complete the final cell of $\mathrm{NiO}+\mathrm{GDC} / \mathrm{LDM} / \mathrm{i}-\mathrm{GDC} /$ BSCF + GDC, the surface of the i-GDC layer was screenprinted on by the blend of composite cathode and then sintered in air at $1000^{\circ} \mathrm{C}\left(\right.$ cell a), $1015^{\circ} \mathrm{C}\left(\right.$ cell b), $1025^{\circ} \mathrm{C}$ (cell c), or $1050^{\circ} \mathrm{C}$ (cell d) for $2 \mathrm{~h}$. In this study, three single-cell sets were fabricated, all of which use a cathode gradient. The composite layer of $50 \mathrm{wt} . \%$ BSCF and $50 \mathrm{wt} . \%$ GDC was applied onto the i-GDC; meanwhile, the composite layer of $90 \mathrm{wt} . \%$ BSCF and $10 \mathrm{wt} . \%$ GDC layer was exposed to the air atmosphere.

The configuration of the fuel cell system of $\mathrm{NiO}+\mathrm{GDC} /$ LDM/i-GDC/GDC-BSCF is shown in Figure 1(a). Two Au wires were connected to the single cell for current collecting, using the Keithley 238 source-measure unit. There is a coil arranged before the cell, which extends the heating time for the inflow. Both the coil and the cell were placed inside a quartz tube, together with a thermocouple which monitors the cell temperature. To activate the anode on-site, an extra $\mathrm{Ni}+\mathrm{GDC}$ disk was attached above the anode. A sketch of the button cell was represented in Figure 1(b). The dimensions of the system are summarized in Figure 1(c).

The cell was operated in a mixture of methane/air with the flow rate of $650 \mathrm{sccm}$ and the molar ratio of $1.5: 1$. The data were collected on the current density and the cell voltage of the fuel cell button for each combination of the sintering temperature of the cathode $(1000,1015,1025$, and $\left.1050^{\circ} \mathrm{C}\right)$ and the cell operating temperatures $(625,650,675$, and $\left.700^{\circ} \mathrm{C}\right)$.

2.2. Artificial Neural Network Models. Artificial neural network (ANN) is an information processing method inspired by the biological nervous systems. An ANN consists of a number of highly interconnected nodes, called neurons, which are able to receive and transmit the data [38, 39]. Feed-forward multilayer architectures, the simplest form of ANNs, are composed of an input layer, one or more hidden layers, and an output layer. The number of neurons in the input and output layers is equal to the number of inputs and outputs in the system to be modeled. Each neuron is linked to all neurons in the following layer by methods of weighted connections. The input of a neuron is the weighted aggregate of the data from its linked neurons. The response or output of a neuron is the transformation of its input using an appropriate activation function. The neurons will equally transmit their responses to all the neurons in the next layer. Input neurons do not activate their inputs; they just receive and send them to all the neurons in the first hidden layer. The number of neurons in the hidden layers is an important parameter which impacts the precision of the estimation. If too few neurons are used, the ANN might not have enough flexibility to satisfactorily approximate the data. However, if larger than the necessary number of neurons is included, the network then becomes overfitting, and it can memorize the data exactly but fail to generalize to a new situation [40]. In general, there is no rule for the number of neurons in the hidden layer, and it is usually determined by experiments. Figure 2 shows a feed-forward artificial neural network (3-5-1) structure with the input of operating temperature, sintering temperature, and current.

The activation function is used to calculate the output response of a neuron and can take any form, linear or nonlinear. The popular activation function, which is also employed in this study, is the logistic sigmoid [41]. The general form of the function is given as $f(x)=1 /\left(1+e^{-x}\right)$.

In order to enhance the performance of the network, the supplied input-output data should be normalized. In this study, the input data $\left(x_{\mathrm{i}}\right)$ are scaled to the normalized value $\left(x_{\text {norm }}\right)$ as follows:

$$
x_{\text {norm }}=0.8 \frac{\left(x-x_{\min }\right)}{x_{\max }-x_{\min }}+0.1,
$$

where $x_{\max }$ and $x_{\min }$ are the maximum and minimum of the experimental data, respectively.

The values of mean squared error (MSE) and coefficient of determination $\left(R^{2}\right)$ are frequently employed to evaluate the performance of the ANN. They were, respectively, calculated as follows [42]:

$$
\begin{aligned}
\text { MSE } & =\frac{1}{n} \sum_{i=1}^{n}\left(t_{i}-a_{i}\right)^{2}, \\
R^{2} & =\frac{\left(\sum_{i=1}^{n}\left(t_{\mathrm{i}}-\bar{t}\right)\left(a_{\mathrm{i}}-\bar{a}\right)\right)^{2}}{\sum_{i=1}^{n}\left(t_{\mathrm{i}}-\bar{t}\right)^{2} \sum_{i=1}^{n}\left(a_{\mathrm{i}}-\bar{a}\right)^{2}},
\end{aligned}
$$

where $n$ is the total data points, $t_{\mathrm{i}}$ is the predicted value from the networks, $a_{\mathrm{i}}$ is the experimental response, and $\bar{t}$ and $\bar{a}$ are the average of predicted value and actual value, respectively.

There are several important factors affecting fuel cell performance, including cathode and anode structure, electrolyte material and thickness, cell temperature, and inlet and outlet gas compositions. In this study, two significant factors, namely, cathode sintering temperature and cell operating temperature, were examined. The range for sintering temperature is from $1000^{\circ} \mathrm{C}$ to $1050^{\circ} \mathrm{C}$, and the range for the operating temperature is from $625^{\circ} \mathrm{C}$ to $700^{\circ} \mathrm{C}$. As depicted in our earlier report, the sintering temperature affects the structure of the obtained cathode. The range for the investigated parameters is explained as follows. At the cathode sintering temperature below $1000^{\circ} \mathrm{C}$, the low degree crystallization of BSCF minimizes the redox reaction, thus reducing the fuel cell performance. On the contrary, the phase compatibility between BSCF and GDC is ensured only up to $1050^{\circ} \mathrm{C}$. Similarly, at the lower operating temperature of $600^{\circ} \mathrm{C}$, there are not enough kinetic rate of ionic conducting, leading to poor performance of the fuel cell. However, at operating temperature over $700^{\circ} \mathrm{C}$, the BSCF crystal becomes instable under the methane/air atmosphere, which limits the performance of the fuel cell.

Therefore, the network architecture is designed with three inputs, one hidden layer, and one output. The inputs are current density, sintering temperature of the cathode, and cell operating temperature. The network was trained using the backpropagation algorithm [43]. The maximum number of epochs and the minimum performance gradient are assigned to 400 and $10^{-5}$, respectively. Training 


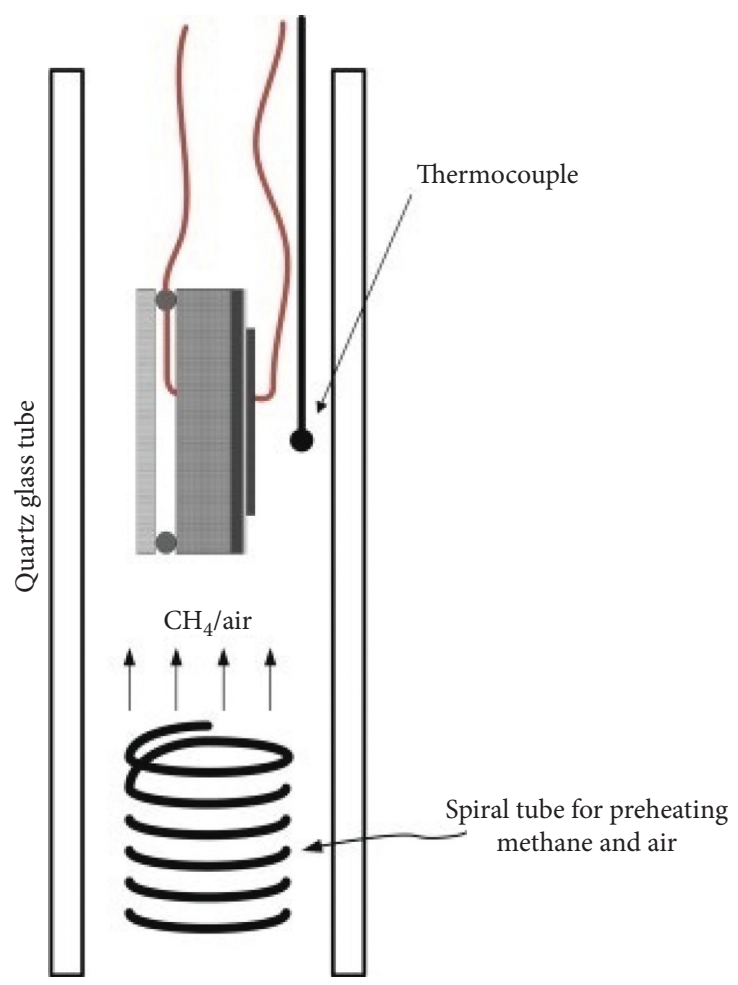

(a)

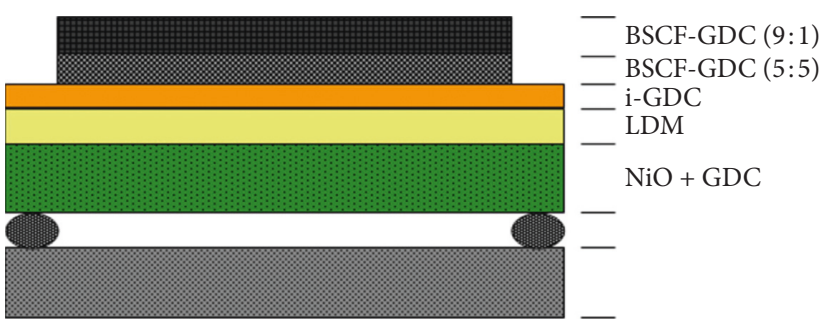

(b)

\begin{tabular}{lc}
\hline Dimensions & $\begin{array}{c}\text { Values } \\
(\mathrm{mm})\end{array}$ \\
\hline Tube length & 45 \\
Tube diameter & 15 \\
Extra disk, anode, electrolyte diameter & 13.5 \\
Extra disk, anode thickness & 0.55 \\
Cathode diameter & 9 \\
Cathode thickness & 0.027 \\
Extra disk to anode distance & 0.15 \\
Electrolyte thickness & 0.06 \\
\hline
\end{tabular}

(c)

Figure 1: (a) Configurations of single-chamber solid oxide fuel cells (SOFCs) and the detail of anode-supported cell [37]. (b) A sketch of the button cell. (c) Geometry dimensions of the experimental setup.

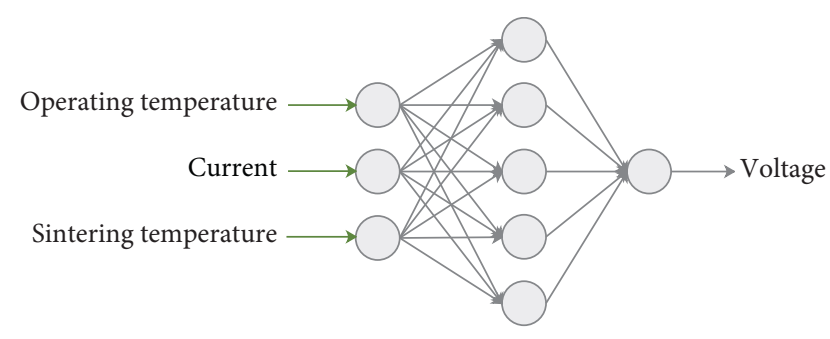

Figure 2: Artificial neural network (3-5-1) structure.

stops when the maximum number of epochs is reached or when either the MSE or performance gradient is less than the predetermined goal. Through various trial experiments, the appropriate network structure for the current simulation is decided. The data sets were randomly divided into three subsets, namely, training, validation, and test, each of which contains $70 \%, 20 \%$, and $10 \%$ number of samples, respectively. The validation and test sets are essential for the evaluation of the validation and modeling power of the networks.

The parameters of the model from the neural network were stored and used to optimize the power density using genetic algorithms in the next section.

2.3. Optimization by Genetic Algorithms. Genetic algorithms (GAs) are heuristic search algorithms inspired by the evolutionary ideas of natural selection and genetics. Genetic algorithms start with randomly generated chromosomes from the feasible region to produce a population. The fitness of each chromosome was defined by the objective function after converting the chromosomes to natural values. The algorithms iteratively modify a population of individual solutions analogous to processes happening in the nature-selection, reproduction, and mutation. The best fitness of the population comes toward an optimal solution by the principle of "survival of the fittest" [44]. The basic steps of genetic algorithms can be summarized as follows:

(1) Randomly generating a primary population of $N$ individuals

(2) Producing the next generation by crossing over and mutation among individuals

(3) Selecting the new population of $N$ individuals from the parents and generation of (2)

(4) Creating the next population by iterating steps (2) and (3) until the maximum number of generations is reached

The algorithm flow of the GA approach is shown in Figure 3.

The objective function in this study is the power density of the fuel cell, which is defined as 


$$
P=I \times V,
$$

where $P$ is the power density $\left(\mathrm{mW} \cdot \mathrm{cm}^{-2}\right), I$ is the current density $\left(\mathrm{mA} \cdot \mathrm{cm}^{-2}\right)$ and is the input to the ANN model, and $V$ is the cell voltage $(\mathrm{V})$ which is estimated from the ANN model.

The design variables in the optimization problem are the inputs of the artificial neural network model. Their corresponding intervals were discussed in the previous section and are summarized as follows:

(i) Sintering temperature of the cathode, [1000-1050] $\left({ }^{\circ} \mathrm{C}\right)$

(ii) Operating temperature of the cell, [625-700] $\left({ }^{\circ} \mathrm{C}\right)$

(iii) Electric current of the cell, [0-1500] $\left(\mathrm{mA} \cdot \mathrm{cm}^{-2}\right)$

The binary GA was used as the optimization method. A MATLAB $^{\mathrm{TM}}$ program which was adapted from the literature [45] is used for the GA computations. The parameters of the GA such as population size and mutation probability values were set to be 100 and 0.10 , respectively. The survival of the chromosomes was determined as the roulette wheel selection with elitism; it means that the best solution is always survive to the next population. The number of generations was assigned to be 500 .

\section{Results and Discussion}

3.1. Microstructure of the Button Cell. In order to better understand the structure of the fabricated single cell, the single cell after $I-V$ measurement was observed using the SEM method. The microstructure of the single cell in a crosssectional image is shown in Figure 4. The SEM image shows an electrolyte thickness of $\sim 60 \mu \mathrm{m}$, total cathode thickness (including 2 layers) of $\sim 27 \mu \mathrm{m}$, and barrier layer i-GDC thickness of $6-8 \mu \mathrm{m}$. Moreover, the cross section shows well adherence between the cathode, i-GDC, electrolyte, and anode layers. Note that a crack of electrolyte at the left-hand side was formed by breaking out for the SEM measurement. Finally, the good adherence between layers and appropriate microstructures reveal that it is a good technique to fabricate the single cell for experimental and simulation study.

3.2. Artificial Neural Network Model Validation. An artificial neural network was used for modeling the cell voltage of the fuel cell. Experimental data obtained under different operating conditions were used to train and validate the neural network model. In ANN modeling, the number of hidden neurons is critical because excessive neurons will cause overfitting; however, too small number of neurons may not adequately capture the complexity of the system [46]. After performing some trials, the sufficient number of neurons in the hidden layer was 7. Consequently, a 3-7-1 feed-forward ANN architecture was employed in this study.

The results of the ANN modeling were described using current versus cell voltage graphs (or $I-V$ plots) and were compared with data from experiments. The correlation coefficients $\left(R^{2}\right)$ for three subsets (training, validation, and testing) were $99.92 \%, 99.88 \%$, and $99.87 \%$, respectively. The

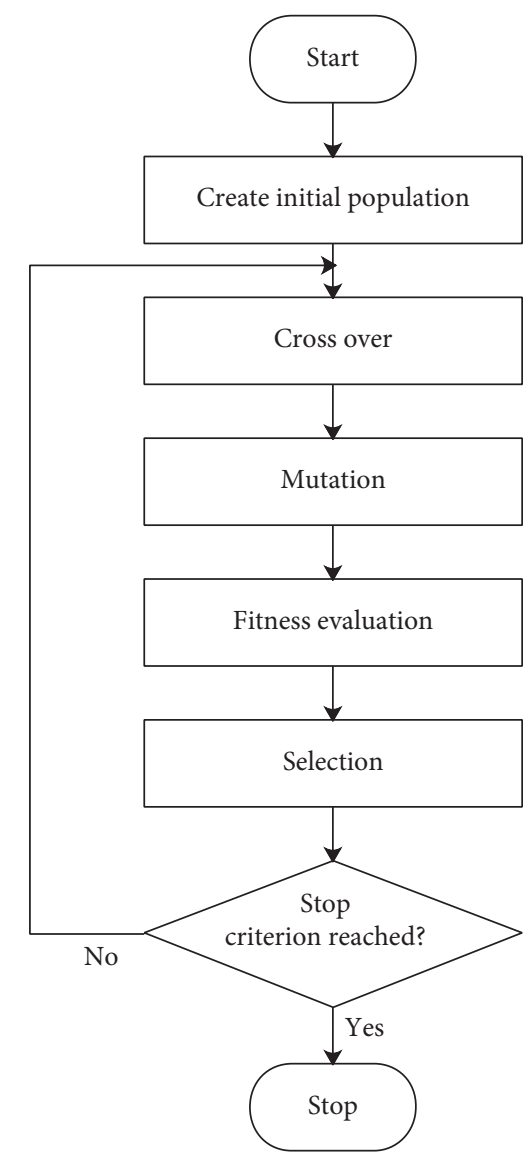

Figure 3: Block diagram of the genetic algorithm process.

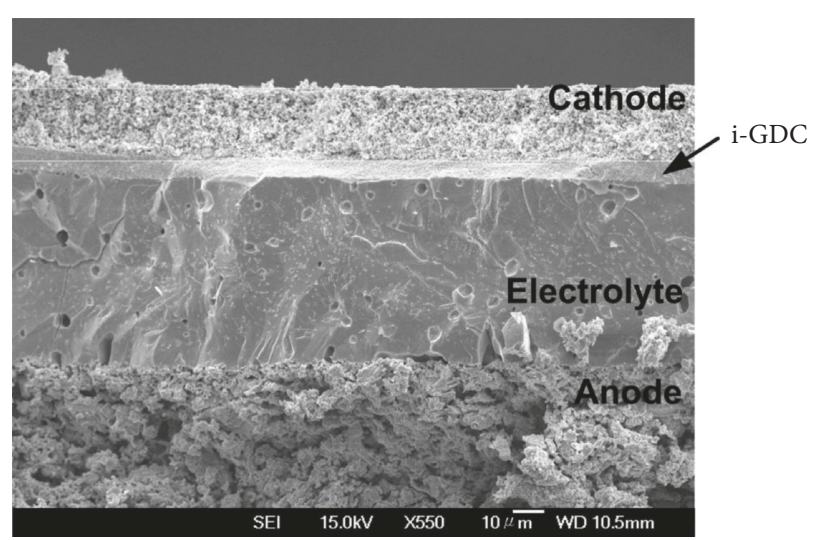

FIgURE 4: The cross-sectional image shows the interface structure of the cell.

MSE values for three subsets (training, validation, and testing) were $4.19 \times 10^{-5}, 7.14 \times 10^{-5}$, and $7.04 \times 10^{-5}$, respectively. The correlation coefficient and MSE of all data were $99.91 \%$ and $5.06 \times 10^{-5}$, respectively.

Figure 5 shows the cell performances from the ANN modeling and the experimental data at the cathode sintering temperature of $1000^{\circ} \mathrm{C}$ as the operating temperature changes from $625^{\circ} \mathrm{C}$ to $700^{\circ} \mathrm{C}$. The correlation and MSE for this subset are $99.95 \%$ and $2.86 \times 10^{-5}$, respectively.

Figure 6 presents the cell voltage versus current density curves of the ANN predictions and the experimental data at 




Figure 5: Comparison of $I-V$ curves for the cathode sintered at $1000^{\circ} \mathrm{C}$ and operated at different temperatures by the ANN model and experimental data.

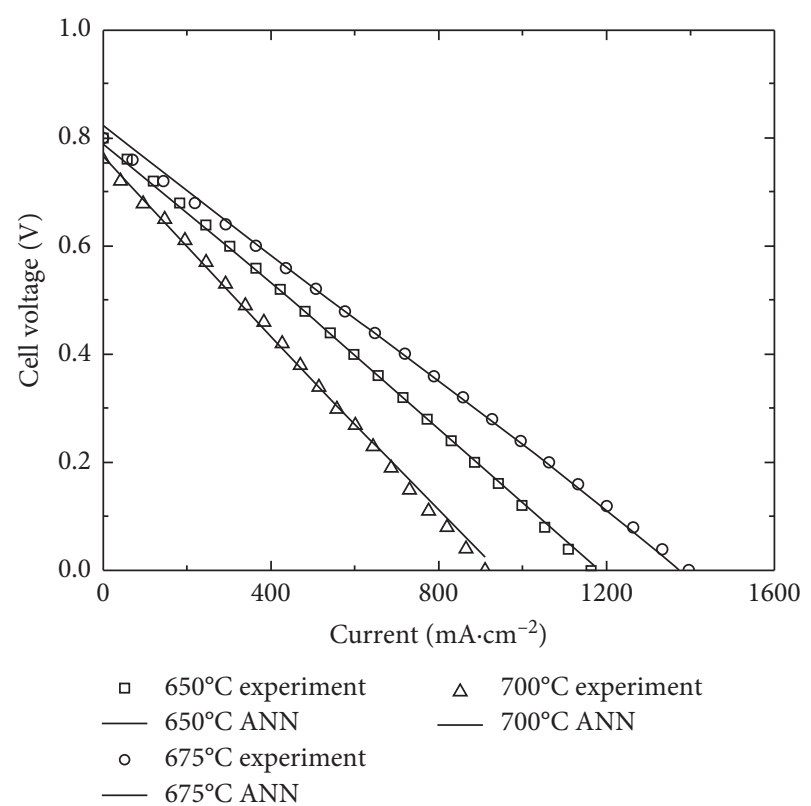

Figure 6: Comparison of $I-V$ curves for the cathode sintered at $1015^{\circ} \mathrm{C}$ and operated at different temperatures by the ANN model and experimental data.

$1015^{\circ} \mathrm{C}$ of cathode sintering temperature as the operating temperature is varied from $650^{\circ} \mathrm{C}$ to $700^{\circ} \mathrm{C}$. The correlation coefficient and MSE of the model for this subset are $99.83 \%$ and $9.74 \times 10^{-5}$, respectively.

In Figure 7, it can be seen that the cell voltage versus current density curves with various operating temperatures modeled by the ANN agrees well with the experimental data at the sintering temperature of $1025^{\circ} \mathrm{C}$. The operating

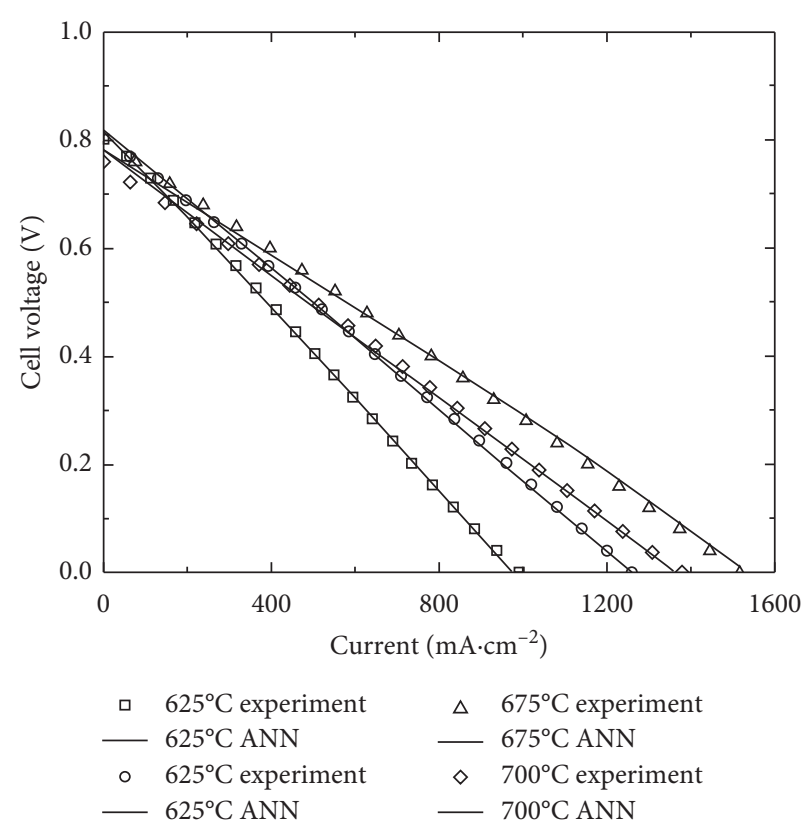

Figure 7: Comparison of $I-V$ curves for the cathode sintered at $1025^{\circ} \mathrm{C}$ and operated at different temperatures by the ANN model and experimental data.

temperature ranges from $625^{\circ} \mathrm{C}$ to $700^{\circ} \mathrm{C}$. The results show that the ANN model is in good agreement with the experimental data with a correlation coefficient of $99.89 \%$ and a MSE of $6.58 \times 10^{-5}$.

Figure 8 shows $I-V$ curves of the cells with the sintering temperature of $1050^{\circ} \mathrm{C}$ from the ANN and experimental data as the operating temperature changes from $650^{\circ} \mathrm{C}$ to $700^{\circ} \mathrm{C}$. The correlation coefficient is $99.98 \%$, and the MSE is $1.28 \times 10^{-5}$ for this subset. The results show a good agreement between the model estimated and the experimental data.

From the results, it can be obtained that the ANN model succeeded in predicting the SOFC performance at an acceptable level of precision. It also confirms the capability of the ANN in investigating the effect of various parameters on its behavior.

3.3. Sensitivity Analysis. In order to identify the critical parameters and their degree of importance on the response outputs, a sensitivity analysis should be investigated. The analysis shows that the network output varies corresponding to the change of inputs and identifies the more sensitive parameters, which should be controlled precisely. The results of this analysis would also contribute deeper understanding about the model parameters for the design process.

In this study, the sensitivity analysis based on the weight matrix was chosen because of its simplicity. From the weight magnitude, several expressions have been proposed which have common properties: calculation of the product of the weights $w_{i j}$ that connects the input neuron $i$ and the hidden neuron $j$ and $v_{j k}$ that connects the hidden neuron $j$ and the output neuron $k$ for each of the 


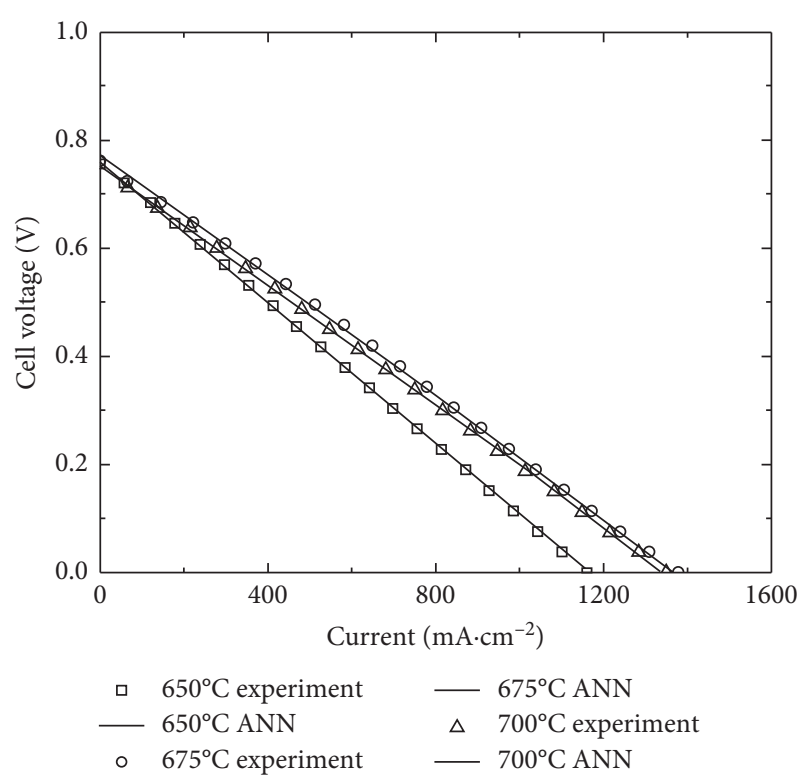

Figure 8: Comparison of $I-V$ curves for the cathode sintered at $1050^{\circ} \mathrm{C}$ and operated at different temperatures by the ANN model and experimental data.

hidden neurons of the network, which gives the sum of the calculated products. The following equation, reported by Garson [47], is widely used:

$$
Q_{i k}=\frac{\sum_{j=1}^{L}\left(\left(w_{i j} / \sum_{r=1}^{N} w_{r j}\right) v_{j k}\right)}{\sum_{i=1}^{N}\left(\sum_{j=1}^{L}\left(\left(w_{i j} / \sum_{r=1}^{N} w_{r j}\right) v_{j k}\right)\right)},
$$

in which $\sum_{r=1}^{N} w_{r j}$ is the sum of the connection weights between the $N$ input neurons and the hidden neuron $j . Q_{i k}$ denotes the effect of the input $i$ on the output $k$, in relation to the other input variables.

The relative significance of each input variable on the output is presented in Figure 9. From the results, it can be obtained that the most important factor affecting the cell voltage is the sintering temperature of the BSCF cathode.

The importance of sintering temperature of the BSCF cathode was also reported in our previous study [36] or it can be seen in Figure 10. From the figure, even though the sintering temperature differs slightly, the cell power performance is significantly affected. Therefore, the sintering temperature should be precisely controlled and carefully decided in order to obtain the cell's best performance.

3.4. Optimization Results. From the artificial neural network modeling results, genetic algorithm was utilized to search the optimum condition for the power density. The decision parameters were the sintering temperature of the cathode, operating temperature of the furnace, and current density. The boundary constraints for the design parameters were indicated earlier in Section 2.3. The fitness function is the power density.

Figure 11 depicts the fitness values (maximum and mean) of the population versus generation. As indicated

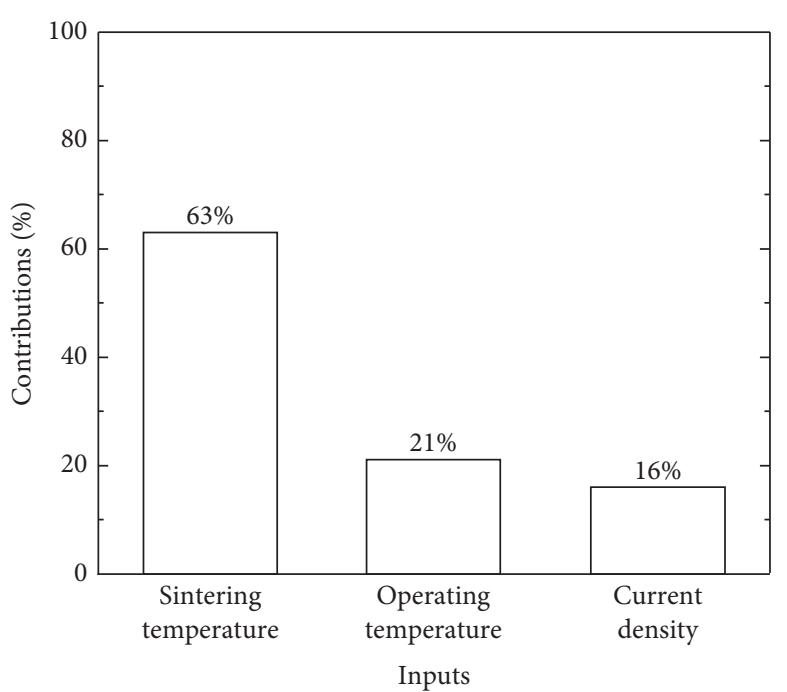

FIGURE 9: Relative contribution of input variables on cell voltage.

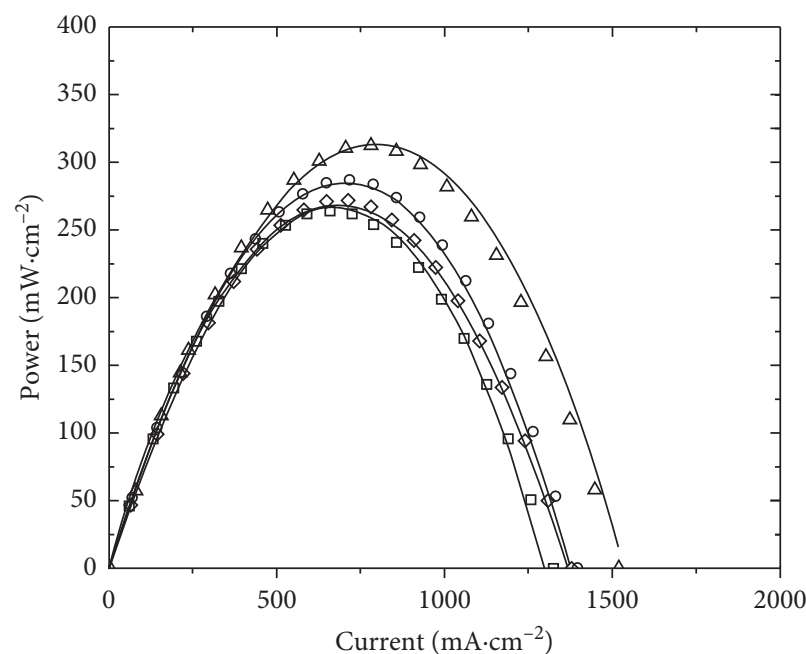

$$
\begin{aligned}
& \text { } 1000^{\circ} \mathrm{C} \text { experiment } \Delta \quad 1025^{\circ} \mathrm{C} \text { experiment } \\
& -1000^{\circ} \mathrm{C} \mathrm{ANN} \quad 1025^{\circ} \mathrm{C} \mathrm{ANN} \\
& \text { - } 1015^{\circ} \mathrm{C} \text { experiment } \diamond 1050^{\circ} \mathrm{C} \text { experiment } \\
& -1015^{\circ} \mathrm{C} \text { ANN } \quad 1050^{\circ} \mathrm{C} \text { ANN }
\end{aligned}
$$

FIGURE 10: The power performance of the cell at different sintering temperatures.

in the figure, after about 20 generations, the value of fitness function attained a maximum value and then remained unchanged. After 100 generations, the maximum fuel cell power density of $451.64 \mathrm{~mW} / \mathrm{cm}^{2}$ could be achieved at the sintering temperature of $1005^{\circ} \mathrm{C}$, operating temperature of $668^{\circ} \mathrm{C}$, and current density of $777 \mathrm{~mA} / \mathrm{cm}^{2}$.

\section{Conclusions}

In this study, an artificial neural network was successfully applied to model the behavior of a BSCF-based singlechamber solid oxide fuel cell. The ANN model can adequately predict the SOFC performance without knowledge of numerous physical, chemical, and electrochemical factors 


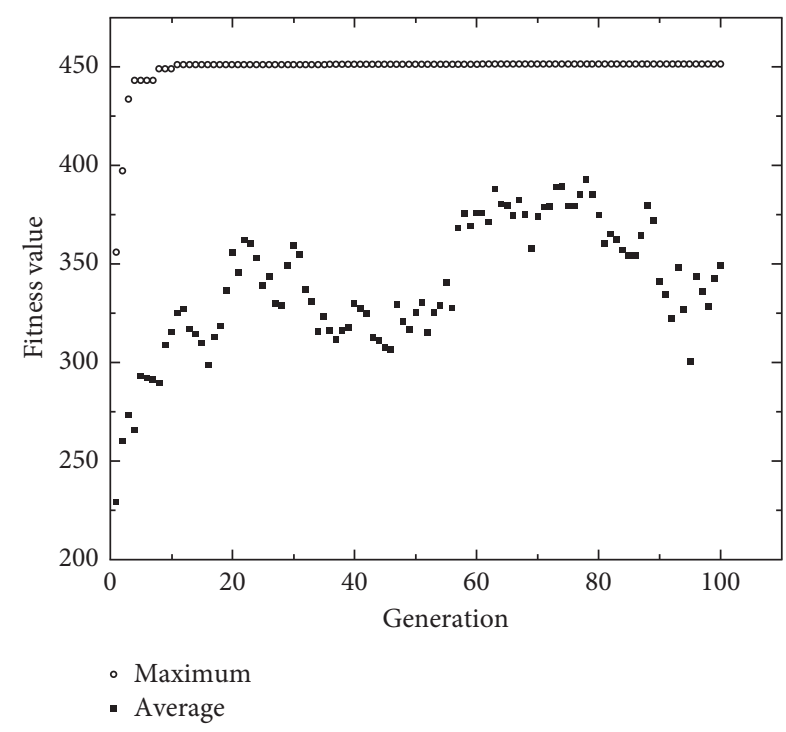

Figure 11: The fitness values versus generation.

and is validated with actual experimental data. The proposed network has a simple structure with one hidden layer and a small number of neurons. The prediction from the ANN model matched the experimental data with a low degree of error. From the trained ANN, the power density was estimated as fitness function, and the genetic optimization algorithm was employed to predict the optimal cell parameters such as sintering temperature of the cathode, operating temperature of the furnace, and current density of the cell. The maximum power density is $451.64 \mathrm{~mW} / \mathrm{cm}^{2}$, which could be achieved at the sintering temperature of $1005^{\circ} \mathrm{C}$, operating temperature of $668^{\circ} \mathrm{C}$, and current density of $777 \mathrm{~mA} / \mathrm{cm}^{2}$. The results suggested that the BSCF should be fabricated at $1005^{\circ} \mathrm{C}$, and the button cell should be operated at $668^{\circ} \mathrm{C}$.

\section{Data Availability}

The data used to support the findings of this study are available from the corresponding author upon request.

\section{Disclosure}

Part of this study (with different cathode materials-LSCF) was presented at the Third International Conference on Computational Science and Engineering in Ho Chi Minh City, Vietnam, November 2016.

\section{Conflicts of Interest}

The authors declare that they have no conflicts of interest.

\section{Acknowledgments}

The authors would like to thank the Vietnam National Foundation for Science and Technology Development (NAFOSTED) for the financial support under grant number 104.03-2013.20. The authors would also like to thank Prof. Dah-Shyang Tsai (National Taiwan University of Science and Technology) for the kind support during the project.

\section{References}

[1] E. D. Wachsman, C. A. Marlowe, and K. T. Lee, "Role of solid oxidefuel cells in a balanced energy strategy," Energy and Environmental Science, vol. 5, no. 2, pp. 5498-5509, 2012.

[2] N. Minh, J. Mizusaki, and S. C. Singhal, "Advances in solid oxide fuel cells: review of progress through three decades of the international symposia on solid oxide fuel cells," ECS Transactions, vol. 78, no. 1, pp. 63-73, 2017.

[3] H. Ghezel-Ayagh and B. P. Borglum, "(Invited) Review of progress in solid oxide fuel cell at FuelCell energy," ECS Transactions, vol. 80, no. 9, pp. 47-56, 2017.

[4] N. Mahato, A. Banerjee, A. Gupta, S. Omar, and K. Balani, "Progress in material selection for solid oxide fuel cell technology: a review," Progress in Materials Science, vol. 72, pp. 141-337, 2015.

[5] L. Fan, B. Zhu, P.-C. Su, and C. He, "Nanomaterials and technologies for low temperature solid oxide fuel cells: recent advances, challenges and opportunities," Nano Energy, vol. 45, pp. 148-176, 2018.

[6] M.-V. Le, D.-S. Tsai, C.-C. Yao, J.-C. Lo, and T. P. G. Vo, "Properties of $10 \%$ Dy-doped $\mathrm{La}_{2} \mathrm{Mo}_{2} \mathrm{O}_{9}$ and its electrolyte performance in single chamber solid oxide fuel cell," Journal of Alloys and Compounds, vol. 582, pp. 780-785, 2014.

[7] D.-S. Tsai, M.-J. Hsieh, J.-C. Tseng, and H.-Y. Lee, "Ionic conductivities and phase transitions of lanthanide rare-earth substituted $\mathrm{La}_{2} \mathrm{Mo}_{2} \mathrm{O}_{9}$," Journal of the European Ceramic Society, vol. 25, no. 4, pp. 481-487, 2005.

[8] T. Jin, M. Madhavarao, C. Cheng, D. Tsai, and M. Hung, "Structural stability and ion conductivity of the Dy and $W$ substituted $\mathrm{La}_{2} \mathrm{Mo}_{2} \mathrm{O}_{9}$," Solid State Ionics, vol. 178, no. 5-6, pp. 367-374, 2007.

[9] Z. Shao and S. M. Haile, "A high-performance cathode for the next generation of solid-oxide fuel cells," Nature, vol. 431, no. 7005 , pp. 170-173, 2004.

[10] W.-X. Kao, M.-C. Lee, T.-N. Lin, C.-H. Wang, and Y.-C. Chang, "Fabrication and characterization of a $\mathrm{Ba}_{0.5} \mathrm{Sr}_{0.5} \mathrm{Co}_{0.8} \mathrm{Fe}_{0.2} \mathrm{O}_{3-\delta^{-}}$Gadolinia-doped ceria cathode for an anode-supported solid-oxide fuel cell," Journal of Power Sources, vol. 195, no. 8, pp. 2220-2223, 2010.

[11] B.-K. Kang, H.-C. Lee, Y.-W. Heo, J.-J. Kim, J. Y. Kim, and J.-H. Lee, "Thermal expansion behavior of La-doped $\left(\mathrm{Ba}_{0.5} \mathrm{Sr}_{0.5} \mathrm{Co}_{0.5} \mathrm{Fe}_{0.2}\right) \mathrm{O}_{3-\delta}$ cathode material," Ceramics International, vol. 39, no. 7, pp. 8267-8271, 2013.

[12] C. Ftikos, S. Carter, and B. C. H. Steele, "Mixed electronic/ionic conductivity of the solid solution $\mathrm{La}_{(1-x)} \mathrm{Sr}_{\mathrm{x}} \mathrm{Co}_{(1-y)} \mathrm{Ni}_{\mathrm{y}} \mathrm{O}_{3-\delta}(x$ : 0.4, 0.5, 0.6 and $y: 0.2,0.4,0.6)$," Journal of the European Ceramic Society, vol. 12, no. 1, pp. 79-86, 1993.

[13] F. S. da Silva and T. M. de Souza, "Novel materials for solid oxide fuel cell technologies: a literature review," International Journal of Hydrogen Energy, vol. 42, no. 41, pp. 26020-26036, 2017.

[14] S. Kakac, A. Pramuanjaroenkij, and X. Zhou, "A review of numerical modeling of solid oxide fuel cells," International Journal of Hydrogen Energy, vol. 32, no. 7, pp. 761-786, 2007.

[15] S. A. Hajimolana, M. A. Hussain, W. M. A. W. Daud, M. Soroush, and A. Shamiri, "Mathematical modeling of solid oxide fuel cells: a review," Renewable and Sustainable Energy Reviews, vol. 15, no. 4, pp. 1893-1917, 2011. 
[16] L. Ma, D. B. Ingham, M. Pourkashanian, and E. Carcadea, "Review of the computational fluid dynamics modeling of fuel cells," Journal of Fuel Cell Science and Technology, vol. 2, no. 4, pp. 246-257, 2005.

[17] K. Wang, D. Hissel, M. C. Péra et al., "A Review on solid oxide fuel cell models," International Journal of Hydrogen Energy, vol. 36, no. 12, pp. 7212-7228, 2011.

[18] M. Karcz, "From 0D to 1D modeling of tubular solid oxide fuel cell," Energy Conversion and Management, vol. 50, no. 9, pp. 2307-2315, 2009.

[19] P. Costamagna, L. Magistri, and A. F. Massardo, "Design and part-load performance of a hybrid system based on a solid oxide fuel cell reactor and a micro gas turbine," Journal of Power Sources, vol. 96, no. 2, pp. 352-368, 2001.

[20] F. Zabihian and A. S. Fung, "Macro-level modeling of solid oxide fuel cells, approaches, and assumptions revisited," Journal of Renewable and Sustainable Energy, vol. 9, no. 5, article 054301, 2017.

[21] T. Ota, M. Koyama, C.-j. Wen, K. Yamada, and H. Takahashi, "Object-based modeling of SOFC system: dynamic behavior of micro-tube SOFC," Journal of Power Sources, vol. 118, no. $1-2$, pp. $430-439,2003$.

[22] P.-W. Li and K. Suzuki, "Numerical modeling and performance study of a tubular SOFC," Journal of The Electrochemical Society, vol. 151, no. 4, pp. A548-A557, 2004.

[23] R. Bove, P. Lunghi, and N. Msammes, "SOFC mathematic model for systems simulations? Part 2: definition of an analytical model," International Journal of Hydrogen Energy, vol. 30, no. 2, pp. 189-200, 2005.

[24] R. Ma, F. Gao, E. Breaz, Y. Huangfu, and B. Pascal, "MultiDimensional reversible solid oxide fuel cell modeling for embedded applications," IEEE Transactions on Energy Conversion, vol. 33, no. 2, pp. 692-701, 2018.

[25] M. Ni, "2D thermal-fluid modeling and parametric analysis of a planar solid oxide fuel cell," Energy Conversion and Management, vol. 51, no. 4, pp. 714-721, 2010.

[26] H. Geisler, S. Dierickx, A. Weber, and E. Ivers-Tiffee, "A 2D stationary FEM model for hydrocarbon fuelled SOFC stack layers," ECS Transactions, vol. 68, no. 1, pp. 2151-2158, 2015.

[27] X. J. Luo and K. F. Fong, "Development of 2D dynamic model for hydrogen-fed and methane-fed solid oxide fuel cells," Journal of Power Sources, vol. 328, pp. 91-104, 2016.

[28] K. Nikooyeh, A. A. Jeje, and J. M. Hill, "3D modeling of anode-supported planar SOFC with internal reforming of methane," Journal of Power Sources, vol. 171, no. 2, pp. 601-609, 2007.

[29] M. Andersson, H. Paradis, J. Yuan, and B. Sundén, "Three dimensional modeling of an solid oxide fuel cell coupling charge transfer phenomena with transport processes and heat generation," Electrochimica Acta, vol. 109, pp. 881-893, 2013.

[30] C. Yang, G. Yang, D. Yue, J. Yuan, and B. Sunden, "Computational fluid dynamics model development on transport phenomena coupling with reactions in intermediate temperature solid oxide fuel cells," Journal of Renewable and Sustainable Energy, vol. 5, no. 2, article 021420, 2013.

[31] H.-B. Huo, X.-J. Zhu, and G.-Y. Cao, "Nonlinear modeling of a SOFC stack based on a least squares support vector machine," Journal of Power Sources, vol. 162, no. 2, pp. 12201225, 2006.

[32] H.-B. Huo, Z.-D. Zhong, X.-J. Zhu, and H.-Y. Tu, "Nonlinear dynamic modeling for a SOFC stack by using a Hammerstein model," Journal of Power Sources, vol. 175, no. 1, pp. 441-446, 2008.
[33] F. Jurado, "A method for the identification of solid oxide fuel cells using a Hammerstein model," Journal of Power Sources, vol. 154, no. 1, pp. 145-152, 2006.

[34] D. E. Goldberg, Genetic Algorithms in Search, Optimization and Machine Learning, Addison-Wesley Longman Publishing Co., Inc., Boston, MA, USA, 1989.

[35] M. Gen and R. Cheng, Genetic Algorithms and Engineering Optimization, Wiley, Hoboken, NJ, USA, 2000.

[36] M.-V. Le, D.-S. Tsai, and T.-A. Nguyen, "BSCF/GDC as a refined cathode to the single-chamber solid oxide fuel cell based on a LAMOX electrolyte," Ceramics International, vol. 44, no. 2, pp. 1726-1730, 2018.

[37] J.-C. Lo, D.-S. Tsai, Y.-C. Chen, M.-V. Le, W.-H. Chung, and F.-J. Liu, " $\mathrm{La}_{2} \mathrm{Mo}_{2} \mathrm{O}_{9}$-Based electrolyte: ion conductivity and anode-supported cell under single chamber conditions," Journal of the American Ceramic Society, vol. 94, no. 3, pp. 806-811, 2011.

[38] J. Milewski and K. Świrski, "Modelling the SOFC behaviours by artificial neural network," International Journal of $\mathrm{Hy}$ drogen Energy, vol. 34, no. 13, pp. 5546-5553, 2009.

[39] D. R. Baughman and Y. A. Liu, Neural Networks in Bioprocessing and Chemical Engineering, Academic Press, Cambridge, MA, USA, 1995.

[40] K. G. Sheela and S. N. Deepa, "Review on methods to fix number of hidden neurons in neural networks," Mathematical Problems in Engineering, vol. 2013, Article ID 425740, 11 pages, 2013

[41] M. Y. Rafiq, G. Bugmann, and D. J. Easterbrook, "Neural network design for engineering applications," Computers and Structures, vol. 79, no. 17, pp. 1541-1552, 2001.

[42] D. M. Himmelblau, "Accounts of experiences in the application of artificial neural networks in chemical engineering," Industrial and Engineering Chemistry Research, vol. 47, no. 16, pp. 5782-5796, 2008.

[43] B. J. Wythoff, "Backpropagation neural networks," Chemometrics and Intelligent Laboratory Systems, vol. 18, no. 2, pp. 115-155, 1993.

[44] R. L. Haupt and S. E. Haupt, Practical Genetic Algorithms, Wiley, Hoboken, NJ, USA, 2004.

[45] C. Guo and X. Yang, "A programming of genetic algorithm in Matlab7.0," Modern Applied Science, vol. 5, no. 1, p. 230, 2011.

[46] D. R. Baughman and Y. A. Liu, Neural Networks in Bioprocessing and Chemical Engineering, Elsevier Science, Amsterdam, Netherlands, 2014.

[47] G. D. Garson, "Interpreting neural-network connection weights,” AI Expert, vol. 6, no. 4, pp. 46-51, 1991. 

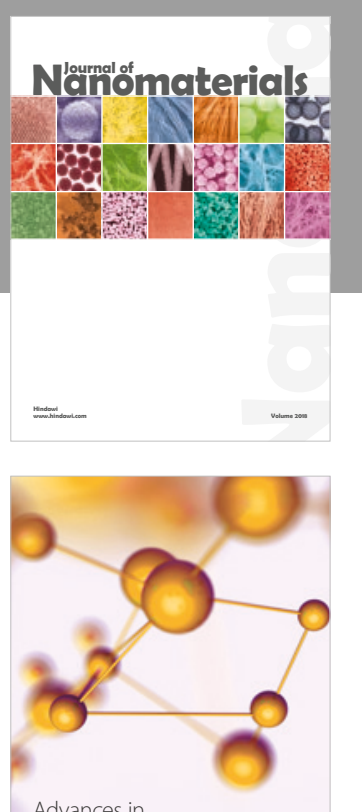

Physical Chemistry




Analytical Methods

in Chemistry

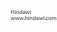

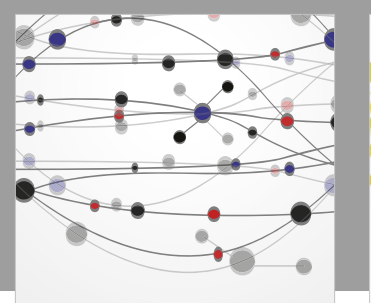

The Scientific World Journal

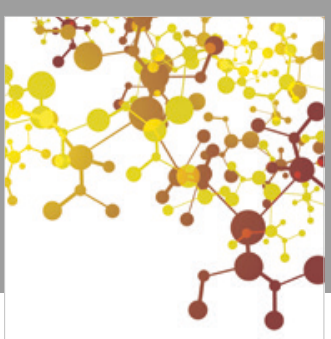

Journal of

Applied Chemistry
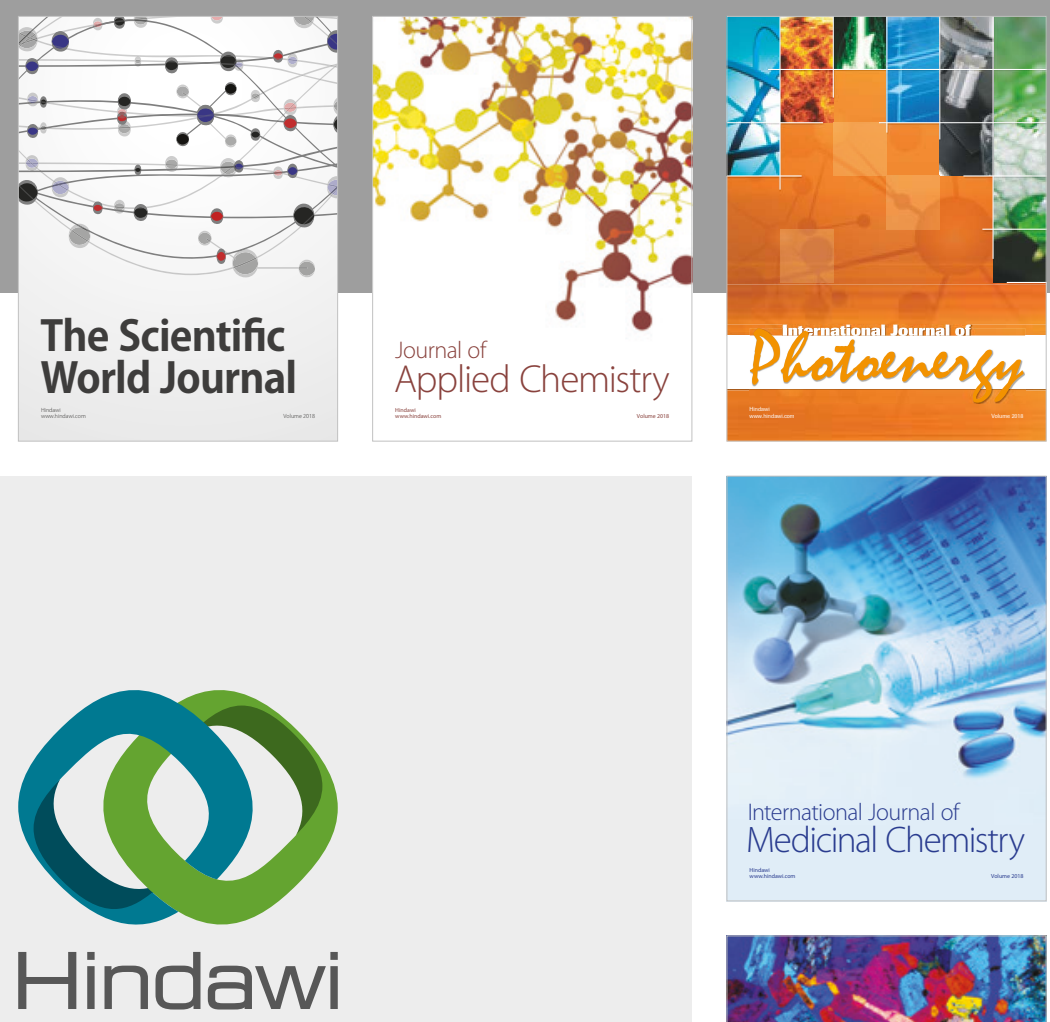

Submit your manuscripts at

www.hindawi.com

